\title{
Rapid Separation and Determination of Process-Related Substances of Paracetamol Using Reversed-Phase HPLC with Photo Diode Array as a Detector
}

\author{
R. Nageswara RaO ${ }^{\dagger}$ and A. Narasaraju \\ HPLC/UV Group, Division of Analytical Chemistry, Discovery Laboratory, \\ Indian Institute of Chemical Technology, Hyderabad-500 007, India
}

\begin{abstract}
A simple and rapid gradient reversed-phase high-performance liquid chromatographic method for simultaneous separation and determination of paracetamol and its related compounds in bulk drugs and pharmaceutical formulations has been developed. As many as nine process impurities and one degradation product of paracetamol have been separated on a Symmetry $\mathrm{C}_{18}$ column $(4.6 \times 250 \mathrm{~mm}$ i.d., particle size $5 \mu \mathrm{m})$ with gradient elution using $0.01 \mathrm{M}$ potassium dihydrogen phosphate buffer ( $\mathrm{pH} 3.0)$ and acetonitrile as mobile phase and photo diode array detection at 215 $\mathrm{nm}$. The chromatographic behavior of all the compounds was examined under variable compositions of different solvents, temperatures, buffer concentrations and $\mathrm{pH}$ values. The correlation coefficients for calibration curves for paracetamol as well as impurities were in the range of $0.9951-0.9994$. The proposed RP-LC method was successfully applied to the analysis of commercial formulations; the recoveries of paracetamol were in the range of $99-101 \%$. The method could be of use not only for rapid and routine evaluation of the quality of paracetamol in bulk drug manufacturing units but also for detection of its impurities in pharmaceutical formulations.
\end{abstract}

(Received March 9, 2005; Accepted May 24, 2005)

\section{Introduction}

Paracetamol, also known as acetaminophen, is one of the popular non-steroidal anti-inflammatory drugs widely used for management of pain and fever in a variety of patients including children, pregnant women, the elderly and those with ostheoartheritis, simple head aches and non-inflammatory musculoskeletol conditions. Accurate determination of paracetamol in pharmaceutical preparations and biological fluids is of great importance not only for quality assurance but also for safety and efficacy studies.

Various analytical methods such as fluorometry, ${ }^{1}$ voltammetry, ${ }^{2}$ Fourier-transform infrared spectrometry, ${ }^{3,4}$ spectrophotometry, ${ }^{5-8}$ flow injection analysis, ${ }^{9}, 10$ chemiluminescence, ${ }^{11}$ electrochemical analysis, ${ }^{12}$ mass spectrometry, ${ }^{13}$ gas chromatography, ${ }^{14}$ capillary electrophoresis ${ }^{15}$ and liquid chromatography ${ }^{16,17}$ were employed for determination of paracetamol. All these methods were used for determination of paracetamol either alone or in combination with other drugs. Under the conditions of high temperature and $\mathrm{pH}$, paracetamol undergoes hydrolysis forming 4-aminophenol and acetic acid as degradation products. ${ }^{18,19}$ In addition to 4 -amino phenol, 4-chloroacetanilide could be one of the major side products of paracetamol. Several HPLC methods using a variety of columns and detection techniques have been proposed and the USP has adopted one of these methods for determination of 4-aminophenol and 4-chloroacetanilide in bulk drugs and formulations of paracetamol. ${ }^{20-22}$ In addition to the above impurities, there are several other process-related impurities that are present at low

$\uparrow$ To whom correspondence should be addressed.

E-mail: rnrao@ins.iictnet.com; rnrao55@yahoo.com levels. These could be precursors, side products formed during the reaction and impurities of the reagents used. Recently, a liquid chromatographic method for simultaneous determination of six such process impurities was reported in the literature. ${ }^{23}$ However, while studying the synthetic process in our laboratory, we discovered the possibility of three more impurities viz., 4aminophenol (I), $N$-(2-hydroxyphenyl)acetamide (V) and 4nitrophenol (X). Here 4-aminophenol (I) and 4-nitrophenol (X) are un-reacted precursors, while $N$-(2-hydroxyphenyl) acetamide $(\mathrm{V})$ is a side product generated during the synthesis.

The present work describes a simple and rapid gradient HPLC method for simultaneous determination of nine impurities and one degradation product of paracetamol. This method is quite suitable for quality assessment of paracetamol in pharmaceutical preparations in the presence of process impurities. The effect of mobile phase composition, buffer concentration, organic modifier and $\mathrm{pH}$ of the buffer on the retention of all the process impurities was studied. The developed method was validated with respect to accuracy, precision and linearity.

\section{Experimental}

Materials and reagents

All reagents were of analytical-reagent grade unless stated otherwise. Glass-distilled and deionized water (Nanopure, Barnsted, USA), HPLC-grade acetonitrile, potassium dihydrogenorthophosphate and orthophosphoric acid (S.D. Fine Chem, Mumbai, India) were used.

\section{Apparatus}

The HPLC system was composed of two LC-10AT VP pumps, 


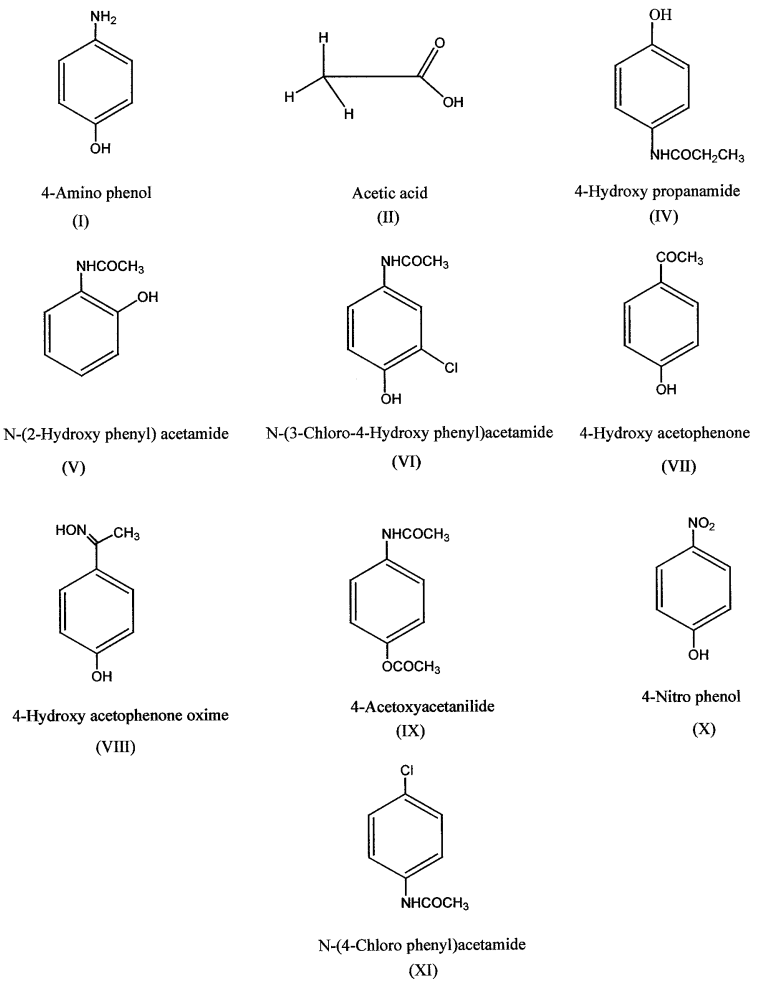

Fig. 1 Process-related impurities, side products and degradation products of paracetamol.

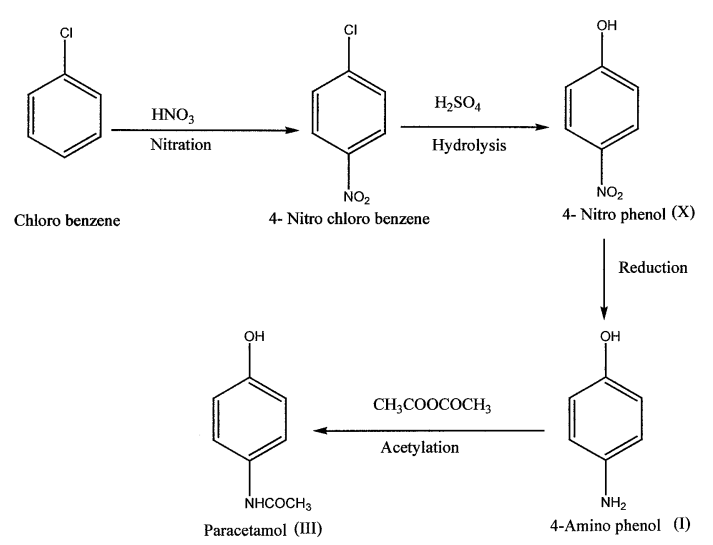

Fig. 2 Synthetic process of paracetamol.

an SPD-M10AVP photo diode array detector, SIL-10AD VP auto injector, a DGU-12A degasser and SCL-10A VP system controller (all from Shimadzu, Kyoto, Japan). A reversed-phase Symmetry $\mathrm{C}_{18}$ (Waters, USA) column $(25 \mathrm{~cm} \times 4.6 \mathrm{~mm}$ i.d.; particle size $5 \mu \mathrm{m}$ ) was used for separation. The chromatographic and the integrated data were recorded using a HP-Vectra (Hewlett Packard, Waldbron, Germany) computer system.

\section{Chromatographic conditions}

Before the mobile phase was delivered into the system, solvent-A containing 0.01 M potassium dihydrogenorthophosphate ( $\mathrm{pH}$ adjusted to 3.0 with orthophosphoric acid) and solvent-B containing acetonitrile were filtered through 0.45 $\mu \mathrm{m}$, PTFE filter and degassed using vacuum. The analysis was carried out using a linear gradient program (Table 1). The flow rate was kept constant at $1.0 \mathrm{ml} / \mathrm{min}$ at room temperature
Table 1 Typical conditions of gradient elution program

\begin{tabular}{ccccl}
\hline $\begin{array}{c}\text { Time/ } \\
\text { min }\end{array}$ & $\begin{array}{c}\text { Flow rate/ } \\
\mathrm{ml} \mathrm{min}^{-1}\end{array}$ & $\begin{array}{c}\text { Solvent } \\
\mathrm{A}, \%\end{array}$ & $\begin{array}{c}\text { Solvent } \\
\mathrm{B}, \%\end{array}$ & Curve \\
\hline 0 & 1.0 & 100 & 0 & Linear \\
30 & 1.0 & 80 & 20 & Linear \\
45 & 1.0 & 45 & 55 & Linear \\
50 & 1.0 & 35 & 65 & Linear \\
52 & 1.0 & 100 & 0 & Linear \\
60 & 1.0 & 100 & 0 & Isocratic \\
\hline
\end{tabular}

Solvent A, $0.01 \mathrm{M} \mathrm{KH}_{2} \mathrm{PO}_{4}(\mathrm{pH}=3.0)$; solvent B, acetonitrile.

$\left(28^{\circ} \mathrm{C}\right)$. The detection was performed at $215 \mathrm{~nm}$ using a SPDM10A VP photo diode array detector.

\section{Analytical procedures}

Solutions $(1000 \mu \mathrm{g} / \mathrm{ml})$ of paracetamol and its process impurities were prepared in the mobile phase by dissolving known amounts of the components in the mobile phase. These solutions were adequately diluted to determine the accuracy, precision, linearity and limits of detection and quantification. Two hundred $\mu \mathrm{g} / \mathrm{ml}$ concentration of paracetamol was taken as a specification level.

\section{Results and Discussion}

\section{Optimization of chromatographic conditions}

The chemical structures of paracetamol (III), acetic acid (II) and all its process-related impurities (I, IV, V, VI, VII, VIII, IX, $\mathrm{X}$ and XI) are shown in Fig. 1. The synthesis of paracetamol is described in Fig. 2. From Fig. 2 it could be seen that compounds $\mathrm{I}$ and $\mathrm{X}$ are precursor impurities generated during the synthesis. Impurities V, VII, IX and XI are side products and IV, VI and VIII are formed because of the impurities present in the reagents used (Fig. 3). Acetic acid (II) is a degradation product.

The present study is aimed at developing a chromatographic system capable of eluting and resolving paracetamol and its impurities. All the impurities and paracetamol were subjected to separation by reversed-phase HPLC on different columns using different buffer systems with different $\mathrm{pH}$ ranges and organic modifiers. The separation and peak shapes were found to be good on Symmetry $\mathrm{C}_{18}(4.6 \times 250) \mathrm{mm}, 5 \mu \mathrm{m}$ column using buffer $0.01 \mathrm{M} \mathrm{KH}_{2} \mathrm{PO}_{4}$ with $\mathrm{pH} 3.0$ adjusted with $\mathrm{H}_{3} \mathrm{PO}_{4}$. When acetonitrile was used as organic modifier, the peaks were sharp and well separated compared to the results for methanol. So acetonitrile was chosen as an organic modifier. Since the impurities possess varying polarities, a gradient method was used. The separation of impurities VII, VIII and IX has become critical as they eluted very close to each other. To achieve this critical separation, we kept the initial concentration of acetonitrile at $0 \%$ in the gradient program. Generally, the use of $100 \%$ aqueous solution as a mobile phase causes irreversible damages to the stationary phase of the $\mathrm{C}_{18}$ columns. However, in the present situation such deleterious effects were not observed due to the following reasons. The hydrolytic and mechanical stability of the packing material used in the Symmetry $\mathrm{C}_{18}$ column was very high. These columns are the perfect choice for applications that require low organic and highly aqueous mobile phase conditions. Further, using the linear gradient program, the percent of organic solvent was gradually increased to $20 \%$ from $0.1 \mathrm{~min}$ to $30 \mathrm{~min}$. Thus, 

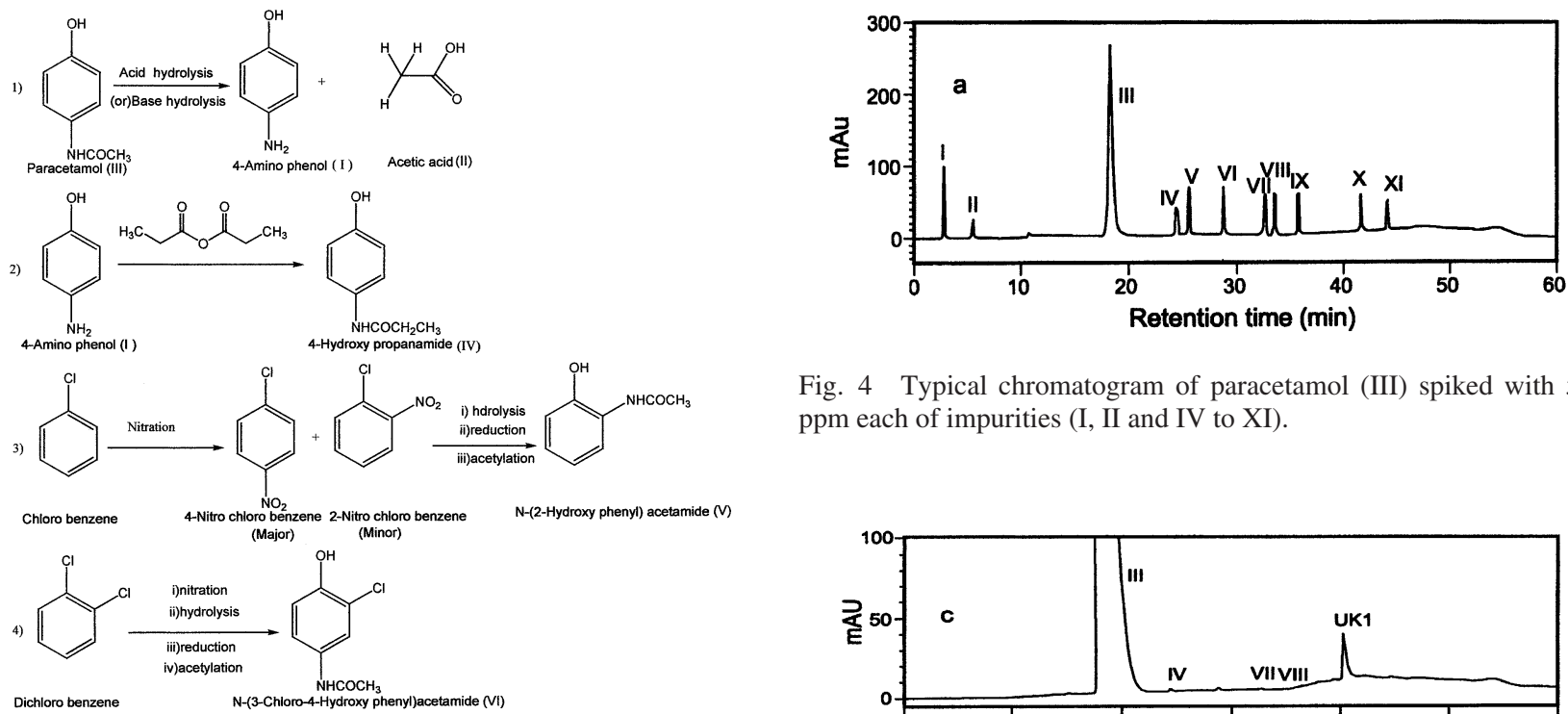

Fig. 4 Typical chromatogram of paracetamol (III) spiked with 50 ppm each of impurities (I, II and IV to XI)
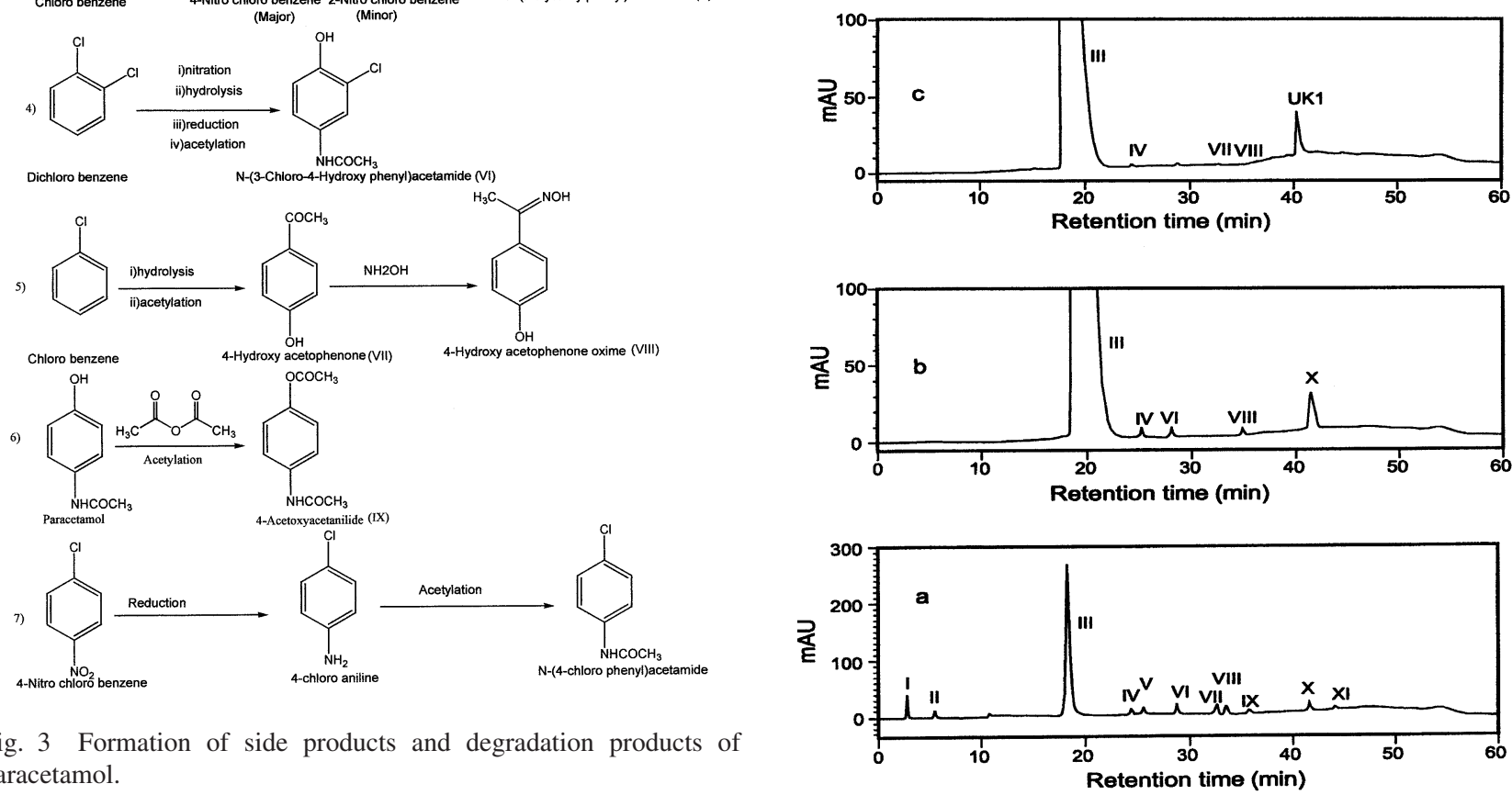

Fig. 3 Formation of side products and degradation products of paracetamol.

$100 \%$ aqueous buffer of $0.01 \mathrm{M}$ potassium dihyrdogenphosphate was allowed on to the column only for $8 \mathrm{~min}$ for stabilization for the next run. This type of reversing the polarity of the mobile phase solvents during a gradient program is quite common and essential to elute unknown impurities of the drugs and pharmaceuticals. Finally, under the selected conditions, all the impurities were well separated (Table 1). A typical chromatogram of paracetamol spiked with $50 \mathrm{ppm}$ of each of the related substances is shown in Fig. 4. It is clear from Fig. 4 that all the compounds were eluted and separated with good peak shapes and resolution. The method was applied to pharmaceutical formulations. Figure 5 describes the separation of impurities in formulations. The peaks were identified by injecting and comparing with the retention times of the individual compounds and by studying the absorption spectra using a PDA detector. An unknown impurity (UK1), which has eluted close to the impurity $\mathrm{X}$ was also well separated under the optimized conditions. The UV wavelength at $215 \mathrm{~nm}$ was chosen for monitoring the separation where all the interested compounds have good absorption. The selectivity was found to be $>1.03$ with resolution $>1.70$ for all the compounds. Further studies were carried out on the effect of temperature, buffer concentration and $\mathrm{pH}$ of the buffer on the retention of all the process impurities. Buffer concentration has no effect on the retentions, whereas retentions were slightly decreased with increasing temperature. So room temperature $\left(28^{\circ} \mathrm{C}\right)$ is

Fig. 5 Typical chromatogram of paracetamol: a) spiked with 20 ppm each of impurities; b), c) commercial tablets of different manufacturers.

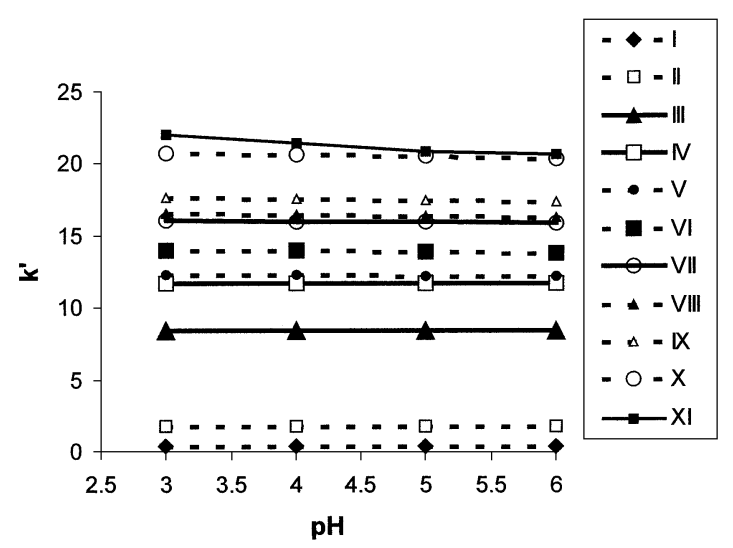

Fig. 6 Effect of $\mathrm{pH}$ on capacity factors $\left(k^{\prime}\right)$.

preferred. The effect of $\mathrm{pH}$ has been shown in Fig. 6. As the $\mathrm{pH}$ value of the buffer was increased, peaks were broadened and resolutions were decreased. So a lower $\mathrm{pH}$ (3.0) was preferred. The developed method was validated with respect to accuracy, 
Table 2 Specificity data

\begin{tabular}{ccc}
\hline \multirow{2}{*}{ No. } & \multicolumn{2}{c}{ Assay of paracetamol, \% } \\
\cline { 2 - 3 } & Without spiking the impurities & Spiked with impurities \\
\hline 1 & 99.89 & 99.87 \\
2 & 99.83 & 99.91 \\
3 & 99.91 & 99.81 \\
Mean & 99.88 & 99.86 \\
SD & 0.04 & 0.05 \\
RSD, $\%$ & 0.04 & 0.05 \\
\hline
\end{tabular}

precision and linearity.

Assay

The assay of paracetamol was estimated using a working standard and the method was validated by the following parameters.

\section{Specificity}

Specificity is the ability of the method to measure the analyte response in the presence of all potential impurities. The results are recorded in Table 2. Chromatographic peak purity and homogeneity was evaluated with a PDA detector. The plot with a flat-top showed that paracetamol exhibited a homogeneous peak with no detectable impurities embedded in it. The specificity was checked by stressing the pure sample under UV light at $254 \mathrm{~nm}, 65^{\circ} \mathrm{C}$ temperature for 15 days and under extreme conditions such as $0.3 \mathrm{~N} \mathrm{HCl}, 0.3 \mathrm{~N} \mathrm{NaOH}$, and $3 \%$ $\mathrm{H}_{2} \mathrm{O}_{2}$. In UV light conditions, no change in the sample purity was observed, but in alkaline and acidic conditions, the degraded products were formed and well separated from paracetamol. In formulations, it was observed that the excipient peaks did not interfere with the peaks of interest (Fig. 5) and that the one unknown impurity (UK1) was well separated from the other impurities. Thus, the method was found to be applicable for quantitative determination of paracetamol in pharmaceutical dosages.

\section{System suitability}

The system suitability was conducted by using $0.3 \%$ of all impurities spiked to the paracetamol $(200 \mu \mathrm{g} / \mathrm{ml})$ and evaluated by making five replicate injections. The system was deemed to be suitable for use if the tailing factors for paracetamol and its impurities were not more than 1.25 and the resolution was not less than 1.70. Synthetic mixtures and process samples were analyzed under identical conditions. The quantities of impurities and assay of paracetamol were calculated from their respective peak areas. The system suitability data are given in Table 3.

\section{Accuracy}

The recoveries of I, IV, V, VI, VII, VIII, IX, X and XI were determined by spiking each impurity at six different levels ranging from $0.30-1.50 \mu \mathrm{g} / \mathrm{ml}$ to the concentration of paracetamol at the specified level $(200 \mu \mathrm{g} / \mathrm{ml})$. In other words, the range of impurities spiked to paracetamol was $0.15-0.75 \%$. The minimum of $0.15 \%$ of each impurity spiked to paracetamol was considered to be the nominal concentration for determining the accuracy of analysis. Acetic acid was spiked at five levels in the range $10-50 \mu \mathrm{g} / \mathrm{ml}$. The recovery range and RSD for all impurities were found to be $93.42-101.22 \%$ and $0.13-2.50 \%$ respectively (Table 4). Similarly, the accuracy of determination of the assay of paracetamol was checked at five-concentration
Table 3 System suitability data

\begin{tabular}{lrlrcl}
\hline Compound & $t_{\mathrm{R}} / \mathrm{min}$ & RRT & \multicolumn{1}{c}{$R_{\mathrm{s}}$} & $\begin{array}{r}\text { Tailing } \\
\text { factor }\end{array}$ & $\begin{array}{c}\text { Response } \\
\text { factor }\end{array}$ \\
\hline I & 2.77 & 0.152 & 0.0 & 1.08 & 0.984 \\
III & 18.25 & 1.00 & 24.50 & 1.05 & 1.0 \\
IV & 24.51 & 1.342 & 9.97 & 1.12 & 0.333 \\
V & 25.64 & 1.404 & 1.87 & 1.10 & 2.56 \\
VI & 28.86 & 1.581 & 3.85 & 1.25 & 0.845 \\
VII & 32.78 & 1.796 & 4.74 & 1.12 & 1.125 \\
VIII & 33.73 & 1.848 & 1.71 & 1.09 & 0.852 \\
IX & 33.73 & 1.848 & 1.71 & 1.13 & 0.507 \\
X & 33.73 & 1.848 & 1.71 & 1.14 & 0.775 \\
XI & 44.24 & 2.423 & 3.31 & 1.17 & 0.326 \\
\hline
\end{tabular}

$t_{\mathrm{R}}$ : retention time.

RRT: relative retention time.

$R_{\mathrm{s}}$ : resolution.

levels: i.e. $100,150,200,250$ and $300 \mu \mathrm{g} / \mathrm{ml}$ each in triplicate for 3 days. The percentage recoveries are recorded in Table 4 . The RSD values are found to be below $1.22 \%$.

\section{Precision}

Six bulk drug samples of paracetamol were obtained from different manufacturers. The precision of the method for impurities was tested by spiking with $0.3 \%$ (w/w) of each impurity to a specified level of $200 \mu \mathrm{g} / \mathrm{ml}$. The recoveries of each impurity were calculated and the RSD was found to be in the range of 0.23 to $2.26 \%$ (Table 5). The precision in determination of assay was studied by repeatability, intermediate precision and reproducibility (ruggedness). Repeatability is the intra-day variation in assay obtained at different concentration levels of paracetamol and is expressed in terms of RSD calculated for each day. The intra-day variations were studied for three successive days at three concentration levels $(100-300 \mu \mathrm{g} / \mathrm{ml})$. The RSD values were found to be below $1.0 \%$ for each day, indicating a good repeatability (Table $6)$. The intermediate precision is the inter-day variation at the same concentration level determined on successive days. The inter-day variations calculated for three concentration levels from the above data are expressed in terms of \% RSD values. At each concentration level, the \% RSD values were below $1.5 \%$, indicating a good intermediate precision. The ruggedness of the method is defined as the degree of reproducibility obtained by the analysis of the same sample under a variety of conditions at different labs, with different analysts using different instruments and different lots of reagents. The same samples of three concentrations were analyzed in triplicate on 2 days by another instrument (LC-10A Module HPLC system containing pump and UV-visible detector) by a different analyst with different lots of reagents and columns. The data obtained were within $2 \%$ RSD.

\section{Linearity}

The linearity of detector response to different concentrations of impurities was studied by analyzing paracetamol spiked with each impurity at ten levels ranging from $0.2-2.0 \mu \mathrm{g} / \mathrm{ml}(50-$ $500 \%$ ). Thus $0.4 \mu \mathrm{g} / \mathrm{ml}$ of impurity was considered to be to $100 \%$. Similarly, the linearity of paracetamol was also studied by preparing standard solutions at ten different levels ranging from 50 to $500 \mu \mathrm{g} / \mathrm{ml}$. The data were subjected to statistical analysis using a linear-regression model; the regression equations and coefficients $\left(r^{2}\right)$ are given in Table 7 . The results have indicated good linearity. 
Table 4 Recovery data of paracetamol and impurities (\% Recovery ( \pm RSD $\%))^{\mathrm{a}}$

\begin{tabular}{|c|c|c|c|c|c|c|}
\hline & \multicolumn{6}{|c|}{$\begin{array}{c}\text { Nominal } 0.15 \% \text { of impurity spiked to paracetamol } \\
\text { Amount added } / \mathrm{mg} \mathrm{ml}^{-1}\end{array}$} \\
\hline & 0.30 & 0.5 & 0.80 & 1.00 & 1.30 & 1.50 \\
\hline a) I & $95.79 \pm 0.68$ & $97.92 \pm 1.66$ & $98.25 \pm 1.66$ & $97.59 \pm 1.79$ & $96.49 \pm 0.63$ & $95.72 \pm 0.50$ \\
\hline b) IV & $97.96 \pm 0.73$ & $102.11 \pm 0.73$ & $94.68 \pm 2.5$ & $99.44 \pm 0.79$ & $94.48 \pm 0.68$ & $93.84 \pm 1.17$ \\
\hline c) V & $103.5 \pm 0.95$ & $97.40 \pm 0.61$ & $98.08 \pm 1.23$ & $101.10 \pm 0.45$ & $95.10 \pm 0.47$ & $95.70 \pm 0.50$ \\
\hline d) VI & $98.92 \pm 0.35$ & $100.75 \pm 0.95$ & $98.12 \pm 1.25$ & $96.83 \pm 1.34$ & $103 \pm 0.91$ & $98.54 \pm 0.55$ \\
\hline e) VII & $96.77 \pm 1.29$ & $102.35 \pm 0.65$ & $97.82 \pm 0.85$ & $96.33 \pm 1.84$ & $95 \pm 2.91$ & $97.54 \pm 0.85$ \\
\hline f) VIII & $100.32 \pm 0.76$ & $101.95 \pm 1.67$ & $103.42 \pm 1.65$ & $96.47 \pm 1.51$ & $101 \pm 1.46$ & $98.59 \pm 1.08$ \\
\hline g) IX & $97.66 \pm 0.53$ & $98.15 \pm 1.07$ & $98.72 \pm 1.35$ & $95.23 \pm 1.44$ & $100.08 \pm 0.91$ & $97.32 \pm 1.37$ \\
\hline h) $X$ & $95.212 \pm 1.91$ & $103.25 \pm 1.28$ & $97.12 \pm 2.25$ & $94.93 \pm 1.61$ & $100.88 \pm 1.11$ & $98.14 \pm 1.45$ \\
\hline i) $\mathrm{XI}$ & $99.72 \pm 0.35$ & $101.15 \pm 0.65$ & $97.34 \pm 0.45$ & $98.83 \pm 1.14$ & $96.82 \pm 1.47$ & $99.264 \pm 1.77$ \\
\hline \multirow[t]{2}{*}{ j) II } & 10 & 20 & 30 & 40 & 50 & \\
\hline & $95.712 \pm 1.31$ & $96.218 \pm 1.01$ & $94.452 \pm 1.82$ & $95.112 \pm 1.95$ & $97.318 \pm 1.24$ & \\
\hline \multirow[t]{2}{*}{ k) III } & 102 & 154 & 203 & 252 & 302 & \\
\hline & $100.88 \pm 0.54$ & $99.35 \pm 0.74$ & $100.98 \pm 0.57$ & $99.72 \pm 1.22$ & $100.40 \pm 0.93$ & \\
\hline
\end{tabular}

a. $n=3$, average of three determinations. RSD: relative standard deviation.

Table 5 Precision data

\begin{tabular}{cc}
\hline Impurity & Mean recovery, $\% \pm$ RSD \\
\hline I & $97.92 \pm 1.89$ \\
III & $102.71 \pm 1.32$ \\
IV & $99.54 \pm 1.54$ \\
V & $99.12 \pm 0.23$ \\
VI & $100.12 \pm 1.51$ \\
VII & $102.08 \pm 0.95$ \\
VIII & $98.92 \pm 0.58$ \\
IX & $101.87 \pm 1.86$ \\
X & $99.64 \pm 0.39$ \\
XI & $98.75 \pm 2.26$ \\
\hline
\end{tabular}

Limits of detection and quantification

Limit of detection (LOD) and quantification (LOQ) represent the concentration of the analyte that would yield signal-to-noise ratios of 3 for LOD and 10 for LOQ, respectively. LOD and LOQ were determined by measuring the magnitude of analytical background by injecting blank samples and calculating the signal-to-noise ratio for each compound by injecting a series of solutions until the $S / N$ ratio 3 for LOD and 10 for LOQ. LOD and LOQ for all compounds lie in the range $(0.05-0.08 \mu \mathrm{g} / \mathrm{ml})$ and $(0.145-0.197 \mu \mathrm{g} / \mathrm{ml})$, respectively. The results are given in Table 7.

The results of analysis of bulk drugs and formulations

High-low chromatographic techniques are employed for detecting trace level impurities in paracetamol bulk drugs and formulations. Three weighed tablets of paracetamol (equivalent to $500 \mathrm{mg}$ each of paracetamol) were ground to powder and an equivalent of $500 \mathrm{mg}$ of active ingredient dissolved in acetonitrile was taken into a $100 \mathrm{ml}$ volumetric flask, ultra sonicated for about $10 \mathrm{~min}$ and made up to the mark with the mobile phase. The supernant liquid was collected. For determining the impurities, one uses the same solution. The results are recorded in Table 8. Almost all the impurities were found in different amounts in all the formulations studied. Formulation 4 has shown the highest amount of impurities $(0.28 \%)$ of which the impurity-IV alone was $0.09 \%$. The assay for determining the paracetamol was carried out by diluting the above solutions to $200 \mathrm{ppm}$ with mobile phase. The results of
Table 6 Inter and intra-day assay of paracetamol

\begin{tabular}{|c|c|c|c|}
\hline \multicolumn{4}{|l|}{ Intra-day } \\
\hline \multicolumn{4}{|l|}{ Day 0} \\
\hline $\begin{array}{l}\text { Mean of concentration/ } \\
\mathrm{mg} \mathrm{ml}^{-1}(n=3)\end{array}$ & 0.108 & 0.206 & 0.304 \\
\hline SD & 0.0004 & 0.0018 & 0.0025 \\
\hline RSD, \% & 0.37 & 0.87 & 0.82 \\
\hline \multicolumn{4}{|l|}{ Day 1} \\
\hline $\begin{array}{l}\text { Mean of concentration/ } \\
\mathrm{mg} \mathrm{ml}^{-1}(n=3)\end{array}$ & 0.105 & 0.205 & 0.302 \\
\hline SD & 0.0006 & 0.0017 & 0.0029 \\
\hline RSD, \% & 0.57 & 0.34 & 0.96 \\
\hline \multicolumn{4}{|l|}{ Day 2} \\
\hline $\begin{array}{l}\text { Mean of concentration/ } \\
\mathrm{mg} \mathrm{m}^{-1}(n=3)\end{array}$ & 0.106 & 0.203 & 0.307 \\
\hline SD & 0.0003 & 0.0016 & 0.0018 \\
\hline RSD, \% & 0.28 & 0.79 & 0.59 \\
\hline \multicolumn{4}{|l|}{ Inter-day } \\
\hline $\begin{array}{l}\text { Mean of concentrations } \\
\text { of three days }\end{array}$ & 0.106 & 0.205 & 0.304 \\
\hline SD & 0.00153 & 0.00153 & 0.00252 \\
\hline RSD, \% & 1.44 & 0.75 & 0.83 \\
\hline
\end{tabular}

assay for bulk drugs and formulations are given in Table 9.

\section{Conclusion}

A gradient RP-HPLC method has been developed and validated for determining as many as nine impurities and one degradation product of paracetamol in bulk drugs and pharmaceuticals. The developed method has been found to be selective, sensitive, precise and stable in determining the paracetamol. The method is also capable of detecting process-related impurities, which may be present at trace level in the finished products.

\section{Acknowledgements}

The authors thanks Dr. J. S. Yadav, Director, Indian Institute of Chemical Technology for encouragement and permission to communicate the results for publication (The IICT communication No. 041112). 
Table 7 Linearity data

\begin{tabular}{|c|c|c|c|c|c|}
\hline Compound & Range/ $/ \mu \mathrm{g} \mathrm{m}^{-1}$ & Regression equation & $r^{2}$ & $\mathrm{LOD} / \mu \mathrm{g} \mathrm{ml} \mathrm{l}^{-1}$ & $\mathrm{LOQ} / \mu \mathrm{g} \mathrm{ml} \mathrm{l}^{-1}$ \\
\hline I & $0.2-2.0$ & $Y=7777 x+4320$ & 0.9971 & 0.05 & 0.145 \\
\hline III & $50-500$ & $Y=2 \times 10^{6} x+2 \times 10^{5}$ & 0.9994 & 0.06 & 0.171 \\
\hline IV & $0.2-2.0$ & $Y=2947 x+754$ & 0.9976 & 0.07 & 0.186 \\
\hline $\mathrm{V}$ & $0.2-2.0$ & $Y=19959 x+11655$ & 0.998 & 0.05 & 0.154 \\
\hline VI & $0.2-2.0$ & $Y=6207 x+4558$ & 0.9956 & 0.07 & 0.183 \\
\hline VII & $0.2-2.0$ & $Y=8592 x+5547$ & 0.9969 & 0.06 & 0.181 \\
\hline VIII & $0.2-2.0$ & $Y=6633 x+4262$ & 0.9985 & 0.07 & 0.191 \\
\hline IX & $0.2-2.0$ & $Y=3855 x+2624$ & 0.9951 & 0.06 & 0.173 \\
\hline$X$ & $0.2-2.0$ & $Y=6170 x+2952$ & 0.9981 & 0.08 & 0.194 \\
\hline XI & $0.2-2.0$ & $Y=2849 x+575$ & 0.990 & 0.07 & 0.197 \\
\hline
\end{tabular}

Table 8 Results of analysis of bulk drugs and formulations by HPLC

\begin{tabular}{lcccccccccccc}
\hline & \multicolumn{10}{c}{ Impurities, \% (w/w) } \\
\cline { 2 - 6 } & I & II & IV & V & VI & VII & VIII & IX & X & XI \\
\hline Bulk-1 & - & - & 0.02 & - & - & 0.02 & 0.01 & - & 0.06 & - \\
Bulk-2 & 0.01 & - & 0.03 & - & - & - & 0.05 & - & - & - \\
Form-1 & - & - & 0.05 & - & - & - & 0.03 & - & 0.01 & - \\
Form-2 & 0.03 & - & 0.02 & - & 0.05 & 0.03 & - & - & - & 0.01 \\
Form-3 & - & - & - & 0.01 & - & - & - & - & - & - \\
Form-4 & - & - & 0.09 & 0.04 & 0.07 & - & - & 0.06 & - & 0.02 \\
Form-5 & - & - & 0.01 & 0.03 & - & - & 0.02 & - & - & - \\
Form-6 & - & - & 0.01 & - & 0.07 & 0.03 & - & 0.04 & - & 0.01 \\
\hline
\end{tabular}

Form: formulation

Bulk: bulk drug.

\section{References}

1. J. L. Vilchez, R. Blanc, R. Avidad, and A. Navalon, $J$. Pharm. Biomed. Anal., 1995, 13, 1119.

2. A. Ivaska, and T. H. Ryan, Collect. Czech. Chem. Commun., 1981, 46, 2865.

3. Z. Bouhsain, S. Garrigues, and M. de la Guardia, Analyst, 1996, 121, 635.

4. M. L. Ramos, J. F. Tyson, and D. J. Curran, Anal. Chim. Acta, 1998, 364, 107.

5. A. Ruiz-Medina, M. I. Fernandez-de Cordova, M. J. AyoraCanada, M. I. Pascual-Reguera, and A. Molina-Diaz, Anal. Chim. Acta, 2000, 404, 131.

6. K. K. Verma, A. K. Gulati, S. Palod, and P. Tyagi, Analyst, 1984, 109, 735.

7. Y. Ni, C. Liu, and S. Kokot, Anal. Chim. Acta, 2000, 419, 185.

8. M. J. Ayora-Canada, M. I. Pascual-Reguera, A. RuizMedina, and M. I. Fernandez-de Cordova, J. Pharm. Biomed. Anal., 2000, 22, 59.

9. Z. Bouhsain, S. Garrigues, A. Morales-Rubio, and M. de la Guardia, Anal. Chim. Acta, 1996, 330, 59.

10. J. A. M. Pulgarin and L. F. G. Bermejo, Anal. Chim. Acta, 1996, 333, 59 .
Table 9 Recovery data of paracetamol from bulk drugs and formulations

\begin{tabular}{lllcl}
\hline \multirow{2}{*}{ Sample } & \multicolumn{2}{c}{ Concentration of paracetamol/mg } & \\
\cline { 2 - 3 } & Taken & Found $^{\mathrm{a}}$ & Recovery, \% & \\
\hline Bulk-1 & 20.452 & 20.525 & 100.36 & 0.21 \\
Bulk-2 & 19.786 & 19.704 & 99.59 & 0.33 \\
Form-1 & 21.32 & 21.289 & 99.85 & 0.42 \\
Form-2 & 20.468 & 20.354 & 99.44 & 0.28 \\
Form-3 & 20.867 & 20.925 & 100.28 & 0.64 \\
Form-4 & 19.355 & 19.180 & 99.10 & 0.23 \\
Form-5 & 20.150 & 20.230 & 100.40 & 0.37 \\
Form-6 & 19.582 & 19.689 & 100.55 & 0.40 \\
\hline
\end{tabular}

a. $n=3$ : average of three injections.

RSD: relative standard deviation.

Bulk: bulk drug.

Form: formulation

11. D. Easwaramoorthy, Y. Yu, and H. Huang, Anal. Chim. Acta, 2001, 439, 95 .

12. I. Christie, S. Leeds, M. Baker, F. Keedy, and P. Vadgama, Anal. Chim. Acta, 1993, 272, 145.

13. J. P. Shockcor, S. E. Unger, I. D. Wilson, P. J. D. Foxall, J. K. Nicholson, and J. C. Lindon, Anal. Chem., 1996, 68, 4431.

14. S. Murray and A. R. Boobis, J. Chromatogr., 1991, 33, 355

15. S. Heitmeier and G. Blaschke, J. Chromatogr., B, 1999, 721,93

16. S. B. Nagaralli, J. Seetharamappa, G. B. Gowda, and B. M. Mahaveer, J. Chromatogr., B, 2003, 798, 49.

17. E. Dinc, J. Pharm. Biomed. Anal., 1999, 21, 723.

18. F. A. Mohamed, M. A. Abdullah, and S. M. Shammat, Talanta, 1997, 44, 61 .

19. M. S. Bloomfield, Talanta, 2002, 58, 1301.

20. I. I. Hewala, Anal. Lett., 1994, 27, 561.

21. J. L. Perez and M. M. Bello, Talanta, 1999, 48, 1199.

22. L. I. Monser and F. Darghouth, J. Pharm. Biomed. Anal., 2002, 27, 851 .

23. M. Kamberi, C. M. Riley, X. Ma, and C. W. C. Huang, J. Pharm. Biomed. Anal., 2004, 34, 123. 